\title{
Facklamia hominis Isolated from a Wound: A Case Report and Review of the Literature
}

\author{
Tae Yeul Kim ${ }^{1 *}$, Juyeon $\mathrm{Jo}^{2}$, Namhee $\mathrm{Kim}^{1,2}$, Hyunwoong Park ${ }^{1,2}$, \\ Eun Youn Roh ${ }^{1,2}$, Jong Hyun Yoon ${ }^{1,2}$, Sue Shin ${ }^{1,2}$ \\ ${ }^{1}$ Department of Laboratory Medicine, Seoul National University College of Medicine, \\ ${ }^{2}$ Department of Laboratory Medicine, Seoul National University Boramae Medical Center, Seoul, Korea
}

Facklamia hominis is a facultative anaerobic Grampositive coccus generally displaying weak alpha-hemolysis and negativity for catalase and oxidase. Facklamia species are part of the normal flora of the female genitourinary tract and have been reported in invasive diseases such as meningitis and infective endocarditis, albeit rarely. A 67 year-old-man presented to hospital with a tender, erythematous epidermal cyst on the right side of his upper back. Simple excision of the cyst was performed and the pus was taken with a sterile swab for culture, yielding no growth. One week later, discharge was observed in the patient's wound site and a sterile swab for culture was taken. The colonies grown were identified as $F$. hominis by the Vitek 2 system (bioMérieux, France), and the result was then reported to clinicians, and later confirmed by $16 \mathrm{~S}$ rRNA gene sequencing and matrix-assisted laser desorption/ionization time-of-flight mass spectrometry. To the best of our knowledge, this is the first reported case of $F$. hominis isolation from a clinical specimen in Korea. (Ann Clin Microbiol 2019;22:50-54)

Key Words: $16 \mathrm{~S}$ rRNA gene sequencing, Facklamia hominis, Wound

\section{INTRODUCTION}

Facklamia hominis는 조건 혐기성 그람양성 구균으로 보통 약한 알파 용혈성을 보이고 카탈라제와 옥시다제 시험에 음성 을 보인다[1]. Collins 등[2]은 API Rapid ID32 Strep과 API ZYM system (bioMérieux, Marcy l'Etoile, France)을 사용한 생 화학적 방법, 전체 세포 단백질에 대한 폴리아크릴아마이드 겔 전기영동법, 그리고 계통유전학적 분석을 이용하여 최초로 $F$. hominis를 동정한 논문을 1997년에 보고한 바 있다. 속명 Facklamia는 미국의 미생물학자 Richard R. Facklam을 기리기 위해 명명되었고[2], 종명 hominis는 세균이 처음으로 분리된 숙주인 인간을 지칭하는 라틴어명사 homo의 소유격에서 유래 되었다. F. hominis 이후, Facklamia ignava [3], Facklamia languida [4], Facklamia sourekii [5], Facklamia miroungae [6], Facklamia tabacinasalis [7]가 추가적으로 동정되었다. Facklamia 종들의 병원성에 대하여 정확히 밝혀진 바는 없지만, 드물게
뇌수막염과 감염성 심내막염 등의 침습적인 감염에서 보고된 바 있기 때문에[1,8-12], 임상미생물 검사실에서의 정확한 동정 이 중요하다. 이에 저자들은 67세 남자 환자의 낭종제거술 후 창상부위에서 무균면봉으로 채취한 분비물로 부터 F. hominis 가 분리된 1 예를 경험하여 문헌고찰과 함께 보고하는 바이다.

\section{CASE REPORT}

67세 남자가 내원 7일 전 상부 등의 오른쪽 부위에 표피 낭 종이 관찰되어 본원 피부과 외래에 내원하였다. 환자는 10 여년 전에 타원에서 $\mathrm{B}$ 형 간염 바이러스에 의한 간경화를 진단받고, 치료받은 병력 외에 다른 기저질환을 가지고 있지 않았다. 내 원 당시 $\mathrm{B}$ 형 간염 표면항원( $\mathrm{HBsAg})$ 은 소실된 상태였고 간기 능은 정상이었다. 낭종은 $2.5 \times 1.7 \times 1.5 \mathrm{~cm}$ 의 크기로 둥근 모양 을 지녔고, 발적과 압통을 동반했다. 환자의 체온은 $36.4^{\circ} \mathrm{C}$ 였 고, 말초혈액검사상 백혈구 $10,140 / \mu \mathrm{L}$ (호중구 $73 \%$, 림프구 
$18 \%$, 단핵구 $7 \%$, 호산구 $1 \%$ ), 혈색소 $15.7 \mathrm{~g} / \mathrm{dL}$, 적혈구 용적 률 $46.6 \%$, 혈소판 $268,000 / \mu \mathrm{L}$ 로 측정되었다. 적혈구 침강 속 도는 $11 \mathrm{~mm} / \mathrm{hr}$ 였고, $\mathrm{CRP}$ 검사는 의뢰되지 않았다. 표피 낭종 을 제거하기 전 염증을 가라앉히기 위해 환자는 cefradine 500 $\mathrm{mg}$ 을 매일 3회 1주일간 경구복용한 후, 성형외과 외래에서 단 순 절제술을 시행받았다. 당시 무균면봉으로 채취한 농양을 혈 액 한천배지, 초콜릿 한천배지(Synergy Innovation, Seongnam, Korea)에서 배양했는데 결과는 음성이었다. 환자는 cefixime $100 \mathrm{mg}$ 을 매일 2회 1주일 동안 경구복용한 후 외래를 방문했 다. 당시 창상 부위에서 분비물이 관찰되었고, 이를 무균면봉으 로 채취하고 변연절제술을 시행했다. 혈액 한천배지와 초콜릿 한천배지에 채취한 분비물을 접종하여 $35^{\circ} \mathrm{C}, 5 \% \mathrm{CO}_{2}$ 배양기 에서 48시간 배양한 후, pinpoint 크기의 하양고 둥근 비용혈성 집락이 관찰되었다. 자란 집락으로 실시한 그람 염색에서 쌍 혹은 사슬모양의 그람양성 구균을 확인했다.

이 분리균주는 Vitek 2 system (bioMérieux)에서 Vitek 2 Gram-positive identification card (bioMérieux)를 이용하여 $F$. hominis로 동정되었고(95.0\%), 그 결과를 임상에 보고했다. 더 정확한 확인을 위해 $16 \mathrm{~S} \mathrm{rRNA}$ 유전자 직접염기서열분석을 실 시하였다. 시발체 $16 \mathrm{~S}-27 \mathrm{~F}$ (5'-AGAGTTTGATCCTGGCTCAG$\left.3^{\prime}\right)$ 와 $16 \mathrm{~S}-1492 \mathrm{R}$ (5'-TACGGTTACCTTGTTACGACTT-3')을 이용하여 $16 \mathrm{~S} \mathrm{rRNA}$ 유전자 절편을 증폭한 후, 시발체 $16 \mathrm{~S}-785 \mathrm{~F}$ (5'-GGATTAGATACCCTGGTA-3')와 16S-907R (5'-CCGTCA ATTCMTTTRAGTTT-3')을 이용하여 직접염기서열분석을 시 행하였다. Trimming 이후 contig가 형성되지 않아, 각각의 염기 서열을 대상으로 GenBank 데이터베이스에 대한 blast 검색을 시행했다. 시발체 $16 \mathrm{~S}-785 \mathrm{~F}$ 로 얻은 염기서열은 F. hominis의 ATCC 700628 strain (GenBank accession no. NR_026393.1)과 $99.54 \%$ 로 가장 높은 상동성을 보였고, 다음으로는 F. languida 1144-97 strain (GenBank accession no. NR_026487.1), F. tabacinasalis GF112B strain (GenBank accession no. NR_026482.1), Globicatella sulfidifaciens CCUG 44365 strain (GenBank accession no. NR_025437.1)이 각각 97.22\%, 96.46\%, 95.84\%의 상동성을 보였다. 시발체 $16 \mathrm{~S}-907 \mathrm{R}$ 로 얻은 염기서열은 $F$. hominis의 ATCC 700628 strain과 99.04\%로 가장 높은 상동성 을 보였고, 다음으로는 F. languida 1144-97 strain, F. miroungae
A/G13/99/2 strain (GenBank accession no. NR_025400.1), $F$. ignava ATCC 700631 strain (GenBank accession no. NR_ $026447.1)$ 이 각각 $96.61 \%, 96.19 \%, 91.56 \%$ 의 상동성을 보였다. F. hominis는 MALDI Biotyper (Bruker Daltonics, Bremen, Germany)에 의해서도 2.024점으로 동정되었다.

Vitek 2 system (bioMérieux)을 이용한 F. hominis 동정 후 즉 시 디스크 확산법을 사용한 항생제 감수성 검사를 실시했고, 그 결과는 Streptococcus spp. viridans group을 위한 Clinical and Laboratory Standards Institute 가이드라인에 따라 해석되었 다[13]. 분리된 균은 erythromycin, clindamycin에 내성을 보였 고, penicillin, chloramphenicol, vancomycin에는 감수성을 보였 다. 환자는 F. hominis 및 연부조직감염을 일으킬 수 있는 흔한 원인균들을 치료하기 위해 amoxicillin/clavulanate $750 \mathrm{mg}$ 을 매 일 3회 1주일간 경구복용한 후, 외래에서 잔여 낭종조직을 제 거하기 위한 소파술을 시행 받았다. 당시 창상 부위에서 감염 의 증거는 발견되지 않았다. 환자는 1 주일 후 변연절제술을 받 고 창상을 일차봉합했다. 창상 부위에 아무 이상이 없어 2주일 후 피부봉합사를 제거했다.

\section{DISCUSSION}

Facklamia 종들은 드물지만 침습적인 감염을 일으킬 가능성 이 있기 때문에, 정확한 동정이 필요하다. Facklamia 종들은 viridans streptococci와 그람염색, 집락형태, 카탈라제, 옥시다 제 반응 등에서 유사하기 때문에, 전통적인 생화학적 검사 중 에서는 pyrrolidonyl arylamidase (PYR)와 leucine aminopeptidase (LAP) 검사만이 이들을 구별해낼 수 있다[14]. Facklamia 종들은 보통 PYR, LAP 검사에 양성이고, viridans streptococci는 이들 검사에 모두 음성이다. 그러나 enterococci 와 같은 그람양성 구균들도 PYR, LAP 검사에 양성이기 때문 에 Facklamia 종들로 잘못 동정될 가능성이 있다. 과거에는 Facklamia 종들이 streptococci나 enterococci로 잘못 동정되는 경우가 많았다[2]. 반대로 수기법으로 생화학적 검사를 시행하 여 Facklamia 종으로 동정했지만, 그 이후에 $16 \mathrm{~S} \mathrm{rRNA}$ 유전자 직접염기서열분석을 통해 Enterococcus faecalis로 밝혀냈던 보 고도 있다[15]. Facklamia 종들은 보통 약한 알파 용혈성을 보

Table 1. Laboratory methods for identification of Facklamia species

\begin{tabular}{lll}
\hline \multicolumn{1}{c}{ Identification methods } & \multicolumn{1}{c}{ Examples } & Facklamia species in the database (database version) \\
\hline Rapid identification systems & Vitek 2 (bioMérieux) & F. hominis (Version R07.01) \\
16S rRNA gene sequencing & In-house commercial kits & All Facklamia species (GenBank database) \\
& Vitek MS (bioMérieux) & F. hominis (Version 3.0) \\
MALDI-TOF-MS & MALDI Biotyper (Bruker Daltonics) & F. hominis, F. languida (Version 6.0.0.0) \\
\hline
\end{tabular}

Abbreviation: MALDI-TOF-MS, Matrix assisted laser desorption/ionization time-of-flight mass spectrometry. 
인다고 알려져 있지만, 비용혈성을 보인 증례가 보고되어 있고 $[9,14]$, 본 환자에서 동정된 F. hominis도 비용혈성을 보였기 때 문에 주의할 필요가 있다.

최근 다양한 생화학적인 검사를 이용하는 신속동정시스템들 은 점점 그들의 데이터베이스에 Facklamia 종들을 포함시켜야 할 필요성을 인식하고 있고, Vitek 2 system (bioMérieux)은 실 제로 F. hominis를 데이터베이스에 포함시켰다[8]. 신속동정시 스템이 적은 비용으로 빠른 검사 결과를 가능하게 해주었지만, 스트레스나 진화에 따라 변화하는 표현형에 의한 오류 가능성 을 항상 염두해야 한다. 특히, PYR 음성인 F. ignava와 F. languida가 보고된 증례가 있기 때문에[14], 표현형 변이에 영향을 받지 않는 $16 \mathrm{~S}$ rRNA 유전자 직접염기서열분석이 생화학적 방 법에 의한 균 동정의 오류를 줄일 수 있다[15]. 또한, F. hominis 는 matrix-assisted laser desorption/ionization time-of-flight mass spectrometry (MALDI-TOF-MS)에 의해 정확한 동정이 가능하 다[11]. 그러나 신속동정시스템과 MALDI-TOF-MS를 사용할 때에는 검사실에서 현재 사용하고 있는 데이터베이스 버전이 어떤 Facklamia 종들을 포함하는지 확인할 필요가 있다. Vitek 2 system의 버전 R07.01과 Vitek MS (bioMérieux)의 버전 3.0 은 F. hominis를 데이터베이스에 포함시켰고, MALDI Biotyper
(Bruker Daltonics)의 버전 6.0.0.0은 F. hominis 뿐만 아니라 $F$. languida도 데이터베이스에 포함했다. Facklamia 종들을 신뢰 성 있게 동정하기 위한 전략들에 대해 Table 1에 설명했다.

Facklamia 종들의 항생제 감수성은 아직 충분히 연구되지 않았고, 전 세계에서 모인 18개의 strain (F. hominis 4개, F. ignava 5개, F. languida 6개, F. sourekii 3개)을 이용한 LaClaire 와 Facklam [16]의 항생제 감수성 연구가 현재까지 가장 대규 모 자료이다. 이 연구에 따르면, 어떤 strain에도 amoxicillin 저 항성은 발견되지 않았지만, 일부 strain들은 cefotaxime (F. ignava 1개, F. sourekii 1개, F. languida 6개)과 cefuroxime ( $F$. hominis 1개, F. languida 5개)에 저항성을 보였다. 대부분의 strain들은 penicillin에 감수성을 보였지만, F. hominis 1개 strain과 $F$. ignava 2개 strain이 중등도의 감수성을 보였다. Macrolide에 대한 저항성은 F. ignava (erythromycin에 3개 strain, clindamycin에 1개 strain)와 F. languida (erythromycin에 2개 strain, clindamycin에 5 개 strain)에서만 관찰되었다. Chloramphenicol, levofloxacin, trovafloxacin, vancomycin에 대한 저항 성은 어떤 strain에서도 발견되지 않았다[16]. 본 증례에서 분리 된 F. hominis는 LaClaire와 Facklam [16]의 연구결과와 유사하 게 penicillin, chloramphenicol, vancomycin에 감수성을 보였지만,

Table 2. Characteristics of Facklamia species isolated from human infections

\begin{tabular}{|c|c|c|c|c|c|c|c|}
\hline \multirow{2}{*}{$\begin{array}{l}\text { Facklamia } \\
\text { Species }\end{array}$} & \multicolumn{2}{|c|}{ Patients } & \multirow{2}{*}{$\begin{array}{l}\text { Sample } \\
\text { Source }\end{array}$} & \multirow{2}{*}{$\begin{array}{l}\text { Identification } \\
\text { methods }\end{array}$} & \multicolumn{2}{|c|}{ Antimicrobial susceptibility testing } & \multirow{2}{*}{ Reference } \\
\hline & Age/Sex & Disease & & & Methods & Results & \\
\hline Unspecified & $41 / \mathrm{F}$ & Meningitis & $\mathrm{CSF}$ & Vitek 2 system & Unspecified & Ceftriaxone (S, MIC: $0.125 \mu \mathrm{g} / \mathrm{mL}$ ) & [1] \\
\hline F. hominis & $35 / \mathrm{M}$ & $\begin{array}{l}\text { Infective } \\
\text { endocarditis }\end{array}$ & Blood & Vitek 2 system & Disk diffusion & $\begin{array}{l}\text { Penicillin (S), amoxicillin (S), } \\
\text { cefotaxime }(\mathrm{S}) \text {, ceftazidime }(\mathrm{S}), \\
\text { ceftriaxone }(\mathrm{S}) \text {, gentamicin }(\mathrm{S}), \\
\text { ciprofloxacin }(\mathrm{S}) \text {, levofloxain }(\mathrm{S}) \text {, } \\
\text { tetracycline }(\mathrm{S}) \text {, rifampicin }(\mathrm{S}), \\
\text { vancomycin }(\mathrm{S})\end{array}$ & [8] \\
\hline F. hominis & Unspecified & $\begin{array}{l}\text { Infective } \\
\text { endocarditis }\end{array}$ & Blood & Unspecified & Unspecified & Penicillin (R) & [9] \\
\hline \multirow[t]{2}{*}{ F. hominis } & $81 / \mathrm{F}$ & $\begin{array}{l}\text { Prosthetic } \\
\text { joint } \\
\text { infection }\end{array}$ & $\begin{array}{l}\text { Joint } \\
\text { samples* }\end{array}$ & $\begin{array}{l}\text { Vitek } 2 \text { system } \\
16 \mathrm{~S} \text { rRNA gene } \\
\text { sequencing }\end{array}$ & Disk diffusion & $\begin{array}{l}\text { Ampicillin (S), oxacillin }(\mathrm{S}), \\
\text { erythromycin }(\mathrm{R}) \text {, clindamycin }(\mathrm{S}) \text {, } \\
\text { trimethoprim-sulfamethoxazole }(\mathrm{S}), \\
\text { tetracycline }(\mathrm{R}) \text {, vancomycin }(\mathrm{S}), \\
\text { linezolid }(\mathrm{S}) \text {, rifampicin }(\mathrm{S})\end{array}$ & [10] \\
\hline & & & & & E-test & $\begin{array}{l}\text { Penicillin (S, MIC: } 0.125 \mu \mathrm{g} / \mathrm{mL} \text { ), } \\
\text { cefotaxime (S, MIC: } 0.38 \mu \mathrm{g} / \mathrm{mL} \text { ), } \\
\text { levofloxacin (S, MIC: } 0.5 \mu \mathrm{g} / \mathrm{mL} \text { ) }\end{array}$ & \\
\hline F. hominis & $40 / \mathrm{F}$ & $\begin{array}{l}\text { Scapular } \\
\text { abscess }\end{array}$ & Pus & MALDI-TOF-MS & Unspecified & $\begin{array}{l}\text { Ceftriaxone }(\mathrm{S}) \text {, gentamicin }(\mathrm{S}) \text {, } \\
\text { erythromycin }(\mathrm{S}) \text {, rifampicin }(\mathrm{S}) \text {, } \\
\text { doxycycline }(\mathrm{S}) \text {, vancomycin }(\mathrm{S}) \text {, } \\
\text { clindamycin }(\mathrm{R})\end{array}$ & [11] \\
\hline F. sourekii & Unspecified & $\begin{array}{l}\text { Necrotizing } \\
\text { gangrene }\end{array}$ & Pus, blood & Unspecified & Unspecified & Vancomycin (S) & [12] \\
\hline
\end{tabular}

*Joint samples consist of two samples from periprosthetic femoral tissue, two samples from femoral interface membrane, and two samples from acetabular interface membrane.

Abbreviations: CSF, cerebrospinal fluid; S, susceptible; R, resistant; MIC, minimum inhibitory concentration; MALDI-TOF-MS, Matrix assisted laser desorption/ionization time-of-flight mass spectrometry. 
erythromycin, clindamycin에 내성을 보였다는 점에서 차이가 있다. 현재까지 인체감염에서 보고된 Facklamia 종들의 분리된 환자와 검체 정보, 동정 방법, 항생제 내성검사 결과를 Table 2 에 정리했다.

Facklamia 종들의 치료에 대해 명확한 가이드라인이 없기 때문에, 항생제 선택은 표준화되지 않은 항생제 감수성 검사결 과에 기초하여 이루어진다[14]. F. hominis에 의한 감염성 심내 막염 증례에서 ceftriaxone, gentamicin 투약으로 성공적으로 치 료가 완료되었고[8], F. hominis에 의한 인공관절 감염 증례에 서는 ceftriaxone, amoxicillin을 투약하여 합병증 발생 없이 감 염이 제거되었다[9]. F. hominis로 인한 어깨농양은 pristinamy$\operatorname{cin}$ 으로 치료받았고, 치료결과에 대해서는 알려진 바가 없다 [11]. F. sourekii에 의한 괴사성 괴저에서는 경험적 항생제로 carbapenem, linezolide가 투약되었고, 배양결과가 나온 후 vancomycin으로 항생제를 변경했으며, 치료 후 환자는 완전히 회 복했다[12].

Facklamia 종들은 드물지만 침습적인 감염을 야기할 수 있 기 때문에 정확한 동정을 위한 전략이 필요하다. Facklamia 종 들이 데이터베이스에 포함된 신속동정시스템, MALDI-TOF-MS, $16 \mathrm{~S}$ rRNA 유전자 직접염기서열분석이 균의 정확한 동정에 매 우 유용하다.

\section{REFERENCES}

1. Parvataneni KC, Iyer S, Khatib R, Saravolatz LD. Facklamia species and Streptococcus pneumoniae meningitis: a case report and review of the literature. Open Forum Infect Dis 2015;2: ofv029.

2. Collins MD, Falsen E, Lemozy J, Akervall E, Sjödén B, Lawson PA. Phenotypic and phylogenetic characterization of some Globicatella-like organisms from human sources: description of Facklamia hominis gen. nov., sp. nov. Int J Syst Bacteriol 1997; 47:880-2.

3. Collins MD, Lawson PA, Monasterio R, Falsen E, Sjöden B,
Facklam RR. Facklamia ignava sp. nov., isolated from human clinical specimens. J Clin Microbiol 1998;36:2146-8.

4. Lawson PA, Collins MD, Falsen E, Sjöden B, Facklam RR. Facklamia languida sp. nov., isolated from human clinical specimens. J Clin Microbiol 1999;37:1161-4.

5. Collins MD, Hutson RA, Falsen E, Sjödén B. Facklamia sourekii sp. nov., isolated from human sources. Int J Syst Bacteriol 1999; 49:635-8.

6. Hoyles L, Foster G, Falsen E, Thomson LF, Collins MD. Facklamia miroungae sp. nov., from a juvenile southern elephant seal (Mirounga leonina). Int J Syst Evol Microbiol 2001;51: 1401-3.

7. Collins MD, Hutson RA, Falsen E, Sjödén B. Facklamia tabacinasalis sp. nov., from powdered tobacco. Int J Syst Bacteriol 1999;49:1247-50.

8. Ananthakrishna R, Shankarappa RK, Jagadeesan N, Math RS, Karur S, Nanjappa MC. Infective endocarditis: a rare organism in an uncommon setting. Case Rep Infect Dis 2012;2012:307852.

9. Safavi S, Tufnell M, Bhalla A. Multi-territory ischaemic strokes and subacute bacterial endocarditis. BMJ Case Rep 2010;2010: bcr0620092023.

10. Corona PS, Haddad S, Andrés J, González-López JJ, Amat C, Flores X. Case report: first report of a prosthetic joint infection caused by Facklamia hominis. Diagn Microbiol Infect Dis 2014; 80:338-40.

11. Abat C, Garcia V, Rolain JM. Facklamia hominis scapula abscess, Marseille, France. New Microbes New Infect 2015;9:13-4.

12. Pérez Alonso AJ, Husein-El Ahmed H, Del Olmo Rivas C, Caballero Marcos L, Pérez Ramon JA. Facklamia sourekii necrotizing gangrene. Med Mal Infect 2012;42:283-4.

13. CLSI. Performance standards for antimicrobial susceptibility testing. CLSI document M100. Wayne, PA: Clinical and Laboratory Standards Institute; 2016.

14. Rahmati E, Martin V, Wong D, Sattler F, Petterson J, Ward P, et al. Facklamia species as an underrecognized pathogen. Open Forum Infect Dis 2017;4:ofw272.

15. Petti CA, Polage CR, Schreckenberger P. The role of $16 \mathrm{~S}$ rRNA gene sequencing in identification of microorganisms misidentified by conventional methods. J Clin Microbiol 2005;43:6123-5.

16. LaClaire L and Facklam R. Antimicrobial susceptibilities and clinical sources of Facklamia species. Antimicrob Agents Chemother 2000;44:2130-2. 
=국문초록=

\section{창상에서 분리된 Facklamia hominis: 증례보고 및 문헌고찰}

${ }^{1}$ 서울대학교 의과대학 검사의학교실, ${ }^{2}$ 서울대학교병원운영 서울특별시보라매병원 진단검사의학과 김태열 ${ }^{1 *}$, 조주연 ${ }^{2}$, 김남희 $^{1,2}$, 박현웅 ${ }^{1,2}$, 노은연 $^{1,2}$, 윤종현 ${ }^{1,2}$, 신 수 $^{1,2}$

Facklamia hominis는 조건 혐기성 그람양성 구균으로 보통 약한 알파 용혈성을 보이고 카탈라제와 옥시다제 시험에 음성 을 보인다. Facklamia 종들은 여성생식기관의 정상세균총의 일부이고, 드물지만 뇌수막염과 감염성 심내막염 등의 침습 적인 감염에서 보고된 바 있다. 10 여년 전 타원에서 $\mathrm{B}$ 형 간염에 의한 간경화를 진단받고 치료받은 것 이외에 다른 기저 질환이 없는 67세 남자가 상부 등의 오른쪽 부위에서 발적과 압통을 동반한 표피 낭종을 주소로 본원 피부과 외래에 내원했다. 성형외과 외래에서 단순 절제술을 시행했고, 무균면봉으로 채취한 농양에 대한 배양검사 결과는 음성이었다. 1 주일 후 성형외과 외래에서 분비물이 창상 부위에서 관찰되었고, 변연절제술과 함께 무균면봉으로 그 분비물을 채취하 여 배양검사를 진행했다. 배양에서 자란 군락들은 Vitek 2 system (bioMérieux, France)에 의해 F. hominis로 동정되어 보고 되었고, $16 \mathrm{~S}$ rRNA 유전자 직접염기서열분석과 matrix-assisted laser desorption/ionization time-of-flight mass spectrometry를 통해 확인되었다. 저자들의 확인에 의하면 본 증례는 F. hominis가 임상검체에서 분리된 국내 첫 증례보고이다. [Ann Clin Microbiol 2019;22:50-54]

교신저자 : 신 수, 07061, 서울시 동작구 보라매로 5길 20

서울대학교병원운영 서울특별시보라매병원 진단검사의학과

Tel: 02-870-2602, Fax: 02-870-2632

E-mail: jeannie@snu.ac.kr 